\title{
Prognostic relevance of protein expression, clinical factors, and MYD88 mutation in primary bone lymphoma
}

\author{
Yong $\mathrm{X} \mathbf{u}^{1, *}$, Jian $\mathrm{Li}^{2}{ }^{*}$, Jian Ouyang ${ }^{1}$, Juan $\mathrm{Li}^{1}$, Jingyan $\mathrm{Xu}^{1}$, Qiguo Zhang ${ }^{1}$, Yonggong \\ Yang ${ }^{1}$, Min Zhou ${ }^{1}$, Jing Wang ${ }^{1}$, Cuiling Zhang ${ }^{1}$, Yueyi Xu ${ }^{1}$, Ping $\mathrm{Li}^{1}$, Rongfu Zhou ${ }^{1}$ \\ and Bing Chen ${ }^{1}$ \\ ${ }^{1}$ Department of Hematology, Affiliated Drum Tower Hospital of Nanjing University Medical School, Nanjing, China \\ ${ }^{2}$ Department of Hematology Oncology, Children's Hospital of Nanjing Medical University, Nanjing, China \\ *Authors contributed equally to this work
}

Correspondence to: Rongfu Zhou, email: rfzhoucn@163.com

Bing Chen, email: chenbing2004@126.com

Keywords: primary bone lymphoma, JAK/STAT, MYD88

Received: May 25, $2017 \quad$ Accepted: July 25, $2017 \quad$ Published: August 04, 2017

Copyright: Xu et al. This is an open-access article distributed under the terms of the Creative Commons Attribution License 3.0 (CC BY 3.0), which permits unrestricted use, distribution, and reproduction in any medium, provided the original author and source are credited.

\section{ABSTRACT}

Primary bone lymphomas (PBLs) are composed of malignant lymphoid cells presenting in osseous sites, without supra-regional lymph node or extranodal involvement. We systematically characterized the immunophenotype and the myeloid differentiation factor 88 (MYD88)-L265P gene mutation status in PBL. Clinical data from 19 patients with PBL treated at Nanjing Drum Tower Hospital between 2009 and 2015 were analyzed retrospectively. Protein expression patterns were identified immunohistochemically, and MYD88 mutation was assessed using polymerase chain reaction and direct DNA sequencing. Fifteen patients presented with diffuse large B-cell lymphoma. Clinical factors favoring a good prognosis were an age $<60$ years and rituximab treatment. B-cell lymphoma 2 expression was detected in 5/15 diffuse large B-cell lymphoma patients, and was associated with a poor prognosis in a univariate model. Janus kinase/signal transducer and activator of transcription 3 (JAK/STAT3) signaling factors were upregulated in PBLs. All eighteen evaluable PBL samples harbored wild-type MYD88. These data thus suggest that age and rituximab treatment are independent prognostic factors determining overall survival, and that activation of JAK/STAT3 signaling may promote the pathogenesis of PBL. Moreover, the absence of MYD88-L265P mutation in PBL indicate there are distinct pathogenetic backgrounds among extranodal lymphomas.

\section{INTRODUCTION}

Lymphoma initiating in the bone is rare, and is designated as primary bone lymphoma (PBL). PBL accounts for less than $7 \%$ of all malignant bone tumors, $5 \%$ of extranodal lymphomas, and $1 \%$ of all malignant lymphomas [1, 2]. According to the 2013 World Health Organization classification of bone/soft tissue tumors, a diagnosis of PBL signifies the presence of one or more skeletal tumors without visceral or regional lymph node involvement. The common sites of PBL are the femur, pelvis, humerus and tibia, but in rare cases, PBL can also affect the small bones of the limbs. Diffuse large B-cell lymphoma (DLBCL) is the most common histological subtype of PBL, while rare categories include follicular lymphoma, peripheral T-cell lymphoma, anaplastic large cell lymphoma (ALCL), extranodal natural killer/T cell lymphoma, and Burkitt's lymphoma [1,3-5]. Until now, only a few studies of PBL have included immunohistochemical and molecular investigations, and little is known about the prognostic significance of the in situ tissue antigen expression profiles in PBL.

In DLBCL, several well-characterized protein signaling cascades are of great benefit for targeted therapy 
strategies, and these signaling pathways can also serve as prognostic markers. For example, signal transducer and activator of transcription 3 (STAT3), a component of the Janus kinase and signal transducer and activator of transcription (JAK/STAT) signal-transducing pathway, is a downstream target of B-cell lymphoma 6 (BCL-6), which has been highly characterized in non-germinal center (GC)-derived DLBCL [6]. The overexpression of cellular myelocytomatosis oncogene (C-MYC; a downstream target of STAT3) integrated with the overexpression of B-cell lymphoma 2 (BCL-2) in DLBCL has been shown to influence the prognosis and predict the therapeutic response in patients receiving chemotherapy [7, 8]. Deregulation of the chemokine receptor 4 (CXCR4)/ proto-oncogene serine/threonine-protein kinases (PIM) cascade also seems to have prognostic and potential therapeutic value in DLBCL [9]. In addition, the activation of nuclear factor $\kappa \mathrm{B}(\mathrm{NF}-\kappa \mathrm{B})$ occurs in most non-germinal center B-cell (non-GCB)-derived DLBCL cases [10], and the first NF- $\mathrm{B}$ pathway inhibitors are currently being tested in clinical studies [11].

Through Sanger sequencing and whole-genome sequencing, a recurrent point mutation resulting in a single nucleotide substitution that changes a leucine to a proline at position 265 (L265P) in the myeloid differentiation factor 88 (MYD88) gene was detected in substantial percentage of DLBCLs, especially in extranodal DLBCLs [12-18]. This was determined to be a gain-offunction mutation that activates the NF- $\mathrm{B}$ pathway to induce tumor cell survival. However, to the best of our knowledge, the frequency of MYD 88 mutations in PBL is still unknown because of the rarity of this tumor type.

In this study, we performed a mutation analysis of the MYD88-L265P mutation in 19 PBL patients, and investigated the immunophenotypic biomarkers and clinicopathological factors associated with PBL.

\section{RESULTS}

\section{Clinicopathological features}

Patient characteristics are shown in Table 1. The median age of the patients at diagnosis was 51 years (range, 15-78 years). The majority of them presented with DLBCL $(n=15 ; 78.9 \%)$, and these patients were further stratified into nine non-GCB patients and six GCB patients. In addition, two anaplastic lymphoma kinase (ALK)-positive ALCLs, one ALK-negative ALCL, and one mantle cell lymphoma (MCL) were identified. The most common presentation was bone pain (100\%). Fourteen patients were classified as having unifocal bone disease, and the other five displayed multifocal bone involvement. The femur was the most commonly affected site in unifocal PBL patients $(28.6 \%)$ at the time of presentation.

\section{Treatments and outcomes}

Patient treatment regimens and outcomes are shown in Table 2. Seventeen patients received combined chemotherapy treatment, and two patients only received surgical treatment. Three patients received chemotherapy with radiotherapy. Three patients received chemotherapy as the initial treatment and cytokine-induced killer (CIK) treatment as consolidation therapy. Two patients (one stage-IVB DLBCL patient and one MCL patient) received chemotherapy as the initial treatment and autologous peripheral blood stem cell transplantation (auto-PBSCT) as consolidation therapy.

After the initial chemotherapy treatment, nine patients achieved complete remission (CR), seven patients achieved partial remission, and one patient experienced disease progression. By the last follow-up, two patients had died due to disease progression, while two patients were alive with the disease. Patients who received CIK treatment or auto-PBSCT were alive with no evidence of disease. One patient with ALK-positive ALCL had received surgical treatment alone, and he remained in $\mathrm{CR}$ for 54 months after surgery.

The median follow-up was 15 months, ranging from 2 months to 60 months. For all patients, the one-year overall survival (OS) and progression-free survival (PFS) rates were $94 \%$ and $67 \%$, respectively, while the estimated two-year OS was $86 \%$. For the 15 DLCBL patients, the one-year OS and PFS rates were 93\% and $60 \%$, respectively, and the estimated two-year OS was $83 \%$. The results of univariate analysis of various factors influencing OS are shown in Table 3. Statistically significant factors that favorably influenced OS were an age $<60$ years and treatment with rituximab.

\section{Immunophenotypic studies and mutational status of $M Y D 88-\mathrm{L} 265 \mathrm{P}$}

The immunophenotypic characteristics of the 19 PBL cases are summarized in Table 4. Immunohistochemistry of a representative sample is presented in Figure 1. Cluster of differentiation 10 (CD10) and mutated melanoma-associated antigen 1 (MUM1) were positive in 4/15 (26.7\%) and 8/15 (53.3\%) DLBCLs, respectively, while BCL-2, BCL-6 and C-MYC were positive in $5 / 15(33.3 \%), 10 / 15(66.7 \%)$ and $7 / 14$ $(50 \%)$ DLBCLs, respectively. Seven of 18 cases expressed CXCR4, and 10/18 (55.6\%) cases expressed PIM1. Proteins expressed in the canonical NF- $\kappa$ B pathway (P50 and P-P65) were also studied. P50 was expressed in 4/18 $(22.2 \%)$ cases, and P-P65 was expressed in 6/18 (33.3\%) cases. In the JAK/STAT pathway, PSTAT3 and JAK2 were evaluated. Nine of 18 evaluable cases expressed PSTAT3. JAK2, a kinase upstream of the STAT pathway, was highly positive in $10 / 18(55.6 \%)$ cases. 
N

\section{Age (years)}

$<60$

$\geq 60$

12

7

Sex

Male

6

Female

Histology

DLBCL

MCL

\section{Initial site (unifocal)}

Femur

Pelvis

Spine

Other

Stage

I/II

IV

\section{LDH}

Normal

Elevated

B symptoms

Yes

$\beta 2-\mathrm{MG}$

Normal

IPI score

0-2

10

9
63.2

$\%$

36.8

68.4

31.6

78.9

5.3

10.5

28.6

21.4

21.4

28.6

52.6

47.4

42.1

21.1

78.9

68.4

31.6

47.3

DLBCL: diffuse large B-cell lymphoma; ALCL: anaplastic large cell lymphoma; ALK: anaplastic lymphoma kinase; MCL: mantle cell lymphoma; LDH: lactate dehydrogenase; $\beta 2-\mathrm{MG}$ : $\beta 2$-microglobulin; IPI: International Prognostic Index

MYD88-L265P mutational status is shown in Table 4, and a representative sequencing read is presented in Figure 2. Eighteen patients had sufficient DNA for MYD88 mutation sequencing by a polymerase chain reaction and Sanger sequencing. All $18 \mathrm{PBL}$ patients harbored wild-type MYD 88 .

\section{Biomarkers and clinicopathological correlations}

The correlations between immunohistochemical markers/clinicopathological factors and OS are listed in Tables 5 and 3 . The median follow-up period was 15 months. The majority of patients received cyclophosphamide, doxorubicin, vincristine, and prednisone (CHOP) alone $(n=6)$ or CHOP combined with rituximab (R-CHOP, $n=9$ ) chemotherapy regimens. BCL-2 seemed to be a marker for poorer OS $(P=0.043)$. C-MYC expression, PIM1 expression and a complete response to initial treatment $(P=0.120, P=0.085, P=$ 0.074 , respectively) exhibited non-significant trends of correlation with OS. Other biomarkers investigated in this study did not correlate with survival. The factors that correlated with OS were chemotherapy combined with rituximab $(P=0.043)$ and an age $<60$ years $(P=0.0069)$. 
Table 2: Treatment regimens and OS/PFS of the 19 PBL patients

\begin{tabular}{lcclccc}
\hline \multicolumn{1}{c}{ No. } & Sex & Age & & Treatment & Outcome & \multicolumn{2}{c}{ Survival time } \\
\hline 1 & & & & OS & PFS \\
2 & M & 45 & R-CHOP, CHOP & ANED & 32 & 32 \\
3 & W & 69 & CHOP, R-CHOP, R-CHOP+MTX, GEMOX, CIK & ANED & 11 & 5 \\
4 & M & 69 & CHOP & Died & 15 & 5 \\
5 & M & 30 & CHOP, R-CHOP, ICE, RA & ANED & 24 & 6 \\
6 & M & 47 & R-CHOP & ANED & 60 & 60 \\
7 & W & 69 & B-CHOP, CHOP, CIK & ANED & 54 & 54 \\
8 & M & 32 & CHOP & ANED & 59 & 59 \\
9 & M & 51 & R-CHOP, Auto-PBSCT & ANED & 15 & 15 \\
10 & W & 53 & SUR & Loss & 2 & 2 \\
11 & W & 68 & R-CHOP, CIK & ANED & 33 & 17 \\
12 & W & 68 & CHOP & Died & 6 & 4 \\
13 & M & 51 & R-CHOP, R-DA-EPOCH, R-DHAP, GEMOX, RA & 9 & 6 \\
14 & M & 54 & R-CHOP, ICE & ANED & 24 & 24 \\
15 & M & 45 & R-CHOP, R-CHOP, R & ANED & 26 & 26 \\
16 & M & 23 & CHOP & ANED & 8 & 8 \\
17 & W & 46 & CHOP & ANED & 48 & 48 \\
18 & M & 78 & CHOP, RA & AWD & 7 & 4 \\
19 & M & 15 & SUR & ANED & 54 & 54 \\
\hline
\end{tabular}

Remark: RA: Radiation therapy; SUR: surgery; MTX: methotrexate;R-CHOP: Rituximab+CHOP; CIK: Cytokineinduced killer; Auto-PBSCT: Autologous peripheral blood stem cell transplantation; ICE: Ifosfamide+Cisplatin+Etoposi de; GEMOX: Gemcitabine+Cisplatin; DHAP: cisplatin+Ara-C+dexamthsone;ANED: Alive with no evidence of disease; AWD: Alive with disease. OS: overall survival; PFS:progression free survival.

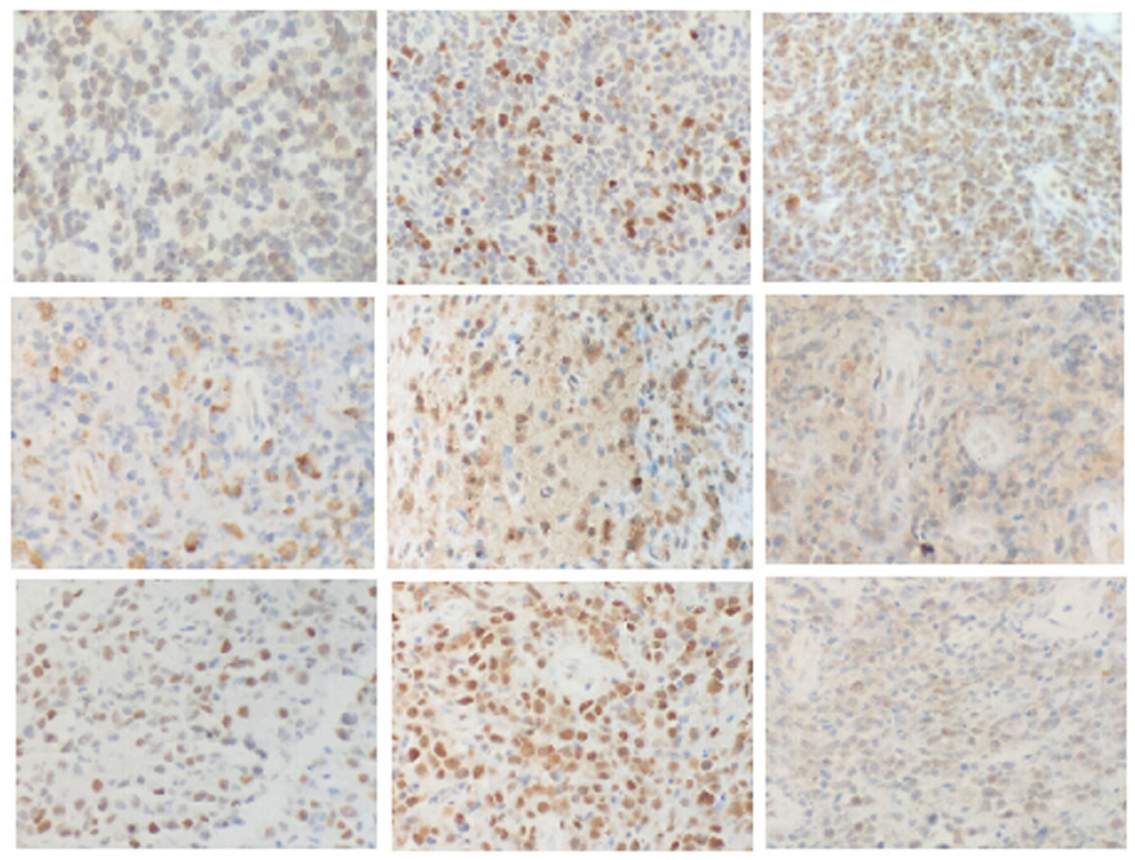

Figure 1: Immunohistochemistry of PBLs. First row, left to right: BCL-2, C-MYC, and CXCR4. Second row, left to right: JAK2, P50, and P-P65. Third row, left to right: P53, PIM1, and PSTAT3. (200×). 


\begin{tabular}{|c|c|c|}
\hline Characteristics & OS (\%) & $P$ value \\
\hline Age (years) & & $0.0069 *$ \\
\hline$<60(n=12)$ & 100 & \\
\hline$\geq 60(n=7)$ & 71.4 & \\
\hline Sex & & 0.449 \\
\hline Male $(n=13)$ & 92.3 & \\
\hline Female $(n=6)$ & 83.3 & \\
\hline LDH & & 0.608 \\
\hline Normal $(n=9)$ & 88.9 & \\
\hline Elevated $(n=10)$ & 90.0 & \\
\hline Stage & & 0.781 \\
\hline $\mathrm{I}-\mathrm{II}(n=10)$ & 90.0 & \\
\hline $\mathrm{IV}(n=9)$ & 88.9 & \\
\hline DLBCL & & 0.234 \\
\hline $\operatorname{GCB}(n=6)$ & 100 & \\
\hline Non-GCB $(n=9)$ & 77.8 & \\
\hline DLBCL treatment & & $0.043 *$ \\
\hline Rituximab $(n=9)$ & 100 & \\
\hline Without Rituximab $(n=6)$ & 66.7 & \\
\hline CR after initial treatment & & 0.074 \\
\hline Yes $(n=10)$ & 100 & \\
\hline No $(n=9)$ & 77.8 & \\
\hline
\end{tabular}

*Indicates statistical significance.

LDH: lactate dehydrogenase; DLBCL: diffuse large B-cell lymphoma; GCB: germinal center B-cell; CR: complete remission.

\section{DISCUSSION}

PBL is a rare extranodal lymphoma subtype that was first described by Parker and Jackson as "reticulum cell sarcoma" [19]. With obvious improvements in imaging technology in recent decades, the proportion of patients diagnosed with PBL has increased. Here, we have described a series of 19 PBL patients from our medical institution. Patients may develop PBL at any age, but elderly patients seem to be affected more frequently. The male:female ratio has been nearly 1.5:1 in some of the most recent large studies, and a similar ratio was observed in our study [20-22]. The median age (51 years) of the patients in this study was similar to those in other clinical series [20-22]. In our series, 14 patients had unifocal bone disease, while the other 5 had multifocal bone involvement. The femur was the most commonly affected site in unifocal PBL patients $(28.6 \%)$ at the time of presentation, followed by the pelvis $(21.4 \%)$ and the spine $(21.4 \%)$. No obvious clinical manifestations were found in early-stage PBLs; however, osteolytic lesions occurred more frequently in advanced disease.

PBL has been described as morphologically heterogeneous, and the overwhelming majority of cases have been characterized as B-cell lineage by immunohistochemistry. As in previous studies, DLBCL was the most common histological subtype (15/19) in our bone lymphoma series. Two extremely rare subtypes, MCL and ALK-negative ALCL, were also identified in our series.

PBL is a distinct subtype of non-hodgkin's lymphoma and usually has favorable clinical features and a good prognosis. Several large studies have demonstrated that the OS of patients with PBL is significantly associated with disease stage and age $[1,3,22]$. In our series, OS did not differ significantly between stage I-II and stage IV patients, and this requires further investigation. Moreover, in the univariate analysis of prognostic factors in PBL, we found that an age $\geq 60$ years was associated with shorter OS. In our study, the one-year OS and PFS rates of all patients were $94 \%$ and $67 \%$, respectively, while the estimated two-year OS was $86 \%$ for all cases. These outcomes were comparable to those previously reported $[1,4,5]$.

Different therapeutic schedules have been used to treat PBL, including surgery, chemotherapy, immunotherapy and radiotherapy. The role of surgery in PBL is limited to sample collection for histopathological diagnosis, stabilization and internal fixation of affected bones, and resolution of pathological 
Table 4: Biomarkers and MYD88-L265P mutation status of PBLs

\begin{tabular}{|c|c|c|c|c|c|c|c|c|c|c|c|c|c|c|c|c|}
\hline \multirow[t]{2}{*}{ Case } & \multirow[t]{2}{*}{ Histology } & \multirow[t]{2}{*}{ CD10 } & \multirow[t]{2}{*}{ BCL-2 } & \multirow[t]{2}{*}{ BCL-6 } & \multirow[t]{2}{*}{ MUM-1 } & \multirow[t]{2}{*}{ C-MYC } & \multirow[t]{2}{*}{ P53 } & \multirow[t]{2}{*}{ P50 } & \multirow[t]{2}{*}{ P65 } & \multirow[t]{2}{*}{ PSTAT3 } & \multirow[t]{2}{*}{ PIM1 } & \multirow[t]{2}{*}{ CXCR4 } & \multirow[t]{2}{*}{ JAK2 } & \multirow[t]{2}{*}{ Subtype } & \multicolumn{2}{|c|}{ MYD88 } \\
\hline & & & & & & & & & & & & & & & L265P AS-PCR & Sequence \\
\hline 1 & DLBCL & - & + & + & + & + & $3+$ & $2+$ & $2+$ & - & + & $2+$ & + & NGCB & - & L265P \\
\hline 2 & DLBCL & - & + & + & + & ND & ND & ND & ND & ND & ND & ND & ND & NGCB & - & ND \\
\hline 3 & DLBCL & - & $3+$ & + & + & $2+$ & + & - & - & - & $3+$ & - & + & NGCB & - & L265P \\
\hline 4 & DLBCL & - & + & - & - & - & - & - & - & - & - & - & $2+$ & NGCB & - & L265P \\
\hline 5 & DLBCL & - & + & + & + & $2+$ & - & - & - & - & $2+$ & $2+$ & + & NGCB & - & L265P \\
\hline 6 & DLBCL & - & + & - & - & $2+$ & - & + & $2+$ & + & - & - & $3+$ & $\mathrm{GCB}$ & - & L265P \\
\hline 7 & DLBCL & - & + & - & + & $2+$ & - & + & - & + & $3+$ & $2+$ & $2+$ & NGCB & - & L265P \\
\hline 8 & DLBCL & - & + & - & - & - & - & - & - & - & + & + & - & GCB & - & L265P \\
\hline 9 & DLBCL & - & + & - & - & $3+$ & - & - & - & - & + & - & - & NGCB & - & L265P \\
\hline 10 & DLBCL & - & $2+$ & + & + & $2+$ & $2+$ & $2+$ & + & $2+$ & $3+$ & - & $2+$ & NGCB & - & L265P \\
\hline 11 & DLBCL & - & $3+$ & + & + & $2+$ & - & + & + & + & $3+$ & - & $2+$ & NGCB & - & L265P \\
\hline 12 & DLBCL & $2+$ & $3+$ & $3+$ & - & + & - & $3+$ & $2+$ & + & $2+$ & $3+$ & $2+$ & $\mathrm{GCB}$ & - & L265P \\
\hline 13 & DLBCL & + & $3+$ & + & + & + & - & $2+$ & $2+$ & + & $2+$ & $2+$ & $3+$ & $\mathrm{GCB}$ & - & L265P \\
\hline 14 & DLBCL & + & + & + & - & - & - & - & - & - & - & - & + & GCB & - & L265P \\
\hline 15 & DLBCL & + & + & + & - & + & $2+$ & + & $3+$ & $2+$ & $3+$ & $3+$ & - & GCB & - & L265P \\
\hline 16 & $\mathbf{A L K}+\mathbf{A L C L}$ & ND & ND & ND & ND & + & - & - & - & - & $3+$ & $2+$ & - & - & - & L265P \\
\hline 17 & ALK-ALCL & ND & ND & ND & ND & - & + & + & + & - & + & - & $3+$ & - & - & L265P \\
\hline 18 & ALK+ALCL & ND & ND & ND & ND & - & $2+$ & + & + & $3+$ & $3+$ & - & $3+$ & - & - & L265P \\
\hline 19 & MCL & - & $3+$ & $2+$ & $2+$ & $2+$ & - & - & $3+$ & + & + & - & $3+$ & - & - & L265P \\
\hline
\end{tabular}

Remark: $+=5-25 \%$ positive tumor cells; $2+=25-75 \%$ positive tumor cells; $3+=>75 \%$ positive tumor cells.

MYD88: Myeloid differentiation factor 88; AS-PCR: Allele-specific polymerase chain reaction; DLBCL: Diffuse Large B-cell Lymphoma; GCB: germinal center B-cell; NGCB: non-germ inal center B-cell; ND: Not Done; ALK: Anaplastic Lymphoma Kinase; ALCL: Anaplastic Large Cell Lymphoma; MCL: mantle cell lymphoma.

Table 5: Results of the biomarker statistical analyses (survival log-rank)

\begin{tabular}{lccc}
\hline & Positive cases (\%) & P value & Cut-off \\
\hline CD10 & $4 / 15(26.7)$ & 0.470 & + \\
MUM1 & $8 / 15(53.3)$ & 0.234 & + \\
BCL-2 & $5 / 15(33.3)$ & $0.043 *$ & ++ \\
BCL-6 & $10 / 15(66.7)$ & 0.220 & + \\
C-MYC & $7 / 14(50)$ & 0.120 & ++ \\
P53 & $6 / 18(33.3)$ & 0.617 & + \\
PSTAT3 & $9 / 18(50)$ & 0.906 & + \\
P50 & $4 / 18(22.2)$ & 0.341 & ++ \\
P65 & $6 / 18(33.3)$ & 0.362 & ++ \\
PIM1 & $10 / 18(55.6)$ & 0.085 & +++ \\
CXCR4 & $7 / 18(38.9)$ & 0.245 & ++ \\
JAK2 & $10 / 18(55.6)$ & 0.981 & ++ \\
\hline
\end{tabular}

Remark 1: $+=5-25 \%$ positive tumor cells; $++=25-75 \%$ positive tumor cells; $+++=>75 \%$ positive tumor cells. CD10, MUM1, BCL-2 and BCL-6 were only investigated in diffuse large B-cell lymphoma (DLBCL) patients.

Remark 2: CD10: cluster of differentiation 10; CD20: cluster of differentiation 20; MUM1: mutated melanoma-associated antigen 1; BCL-2: B-cell lymphoma 2; BCL-6: B-cell lymphoma 6; C-MYC: cellular myelocytomatosis oncogene; P53: phosphoprotein 53; PSTAT3: Phosphorylated signal transducer and activator of transcription 3; PIM1: proto-oncogene serine/ threonine-protein kinases; CXCR4: chemokine receptor 4; JAK2: Janus kinase 2.

fractures. Interestingly, one ALK+ALCL patient who only accepted surgical treatment was still alive without disease progression up to the last follow-up (54 months). Anthracycline-based chemotherapy such as CHOP (cyclophosphamide, doxorubicin, vincristine, prednisone), is the first-choice regimen for PBL-DLBCL. In our study, most of the DLBCL patients received CHOP or CHOP-like regimens and achieved a good CR rate. The 
survival benefit or potential complications of irradiating the affected bones after primary chemotherapy in patients with PBL are a matter of debate [5]. Prospective studies focused on this therapeutic issue in patients with PBL do not exist, thus, debate is mostly based on circumstantial evidence from large trials in nodal DLBCL. Here, a limitation of our study was that only three patients received radiation therapy after chemotherapy, due to disease progression.

Whether the anti-CD20 monoclonal antibody rituximab combined with a CHOP regimen can improve the prognosis of PBL has not been demonstrated. A few retrospective studies have suggested that the addition of rituximab is beneficial, as the three-year PFS rate was 50-
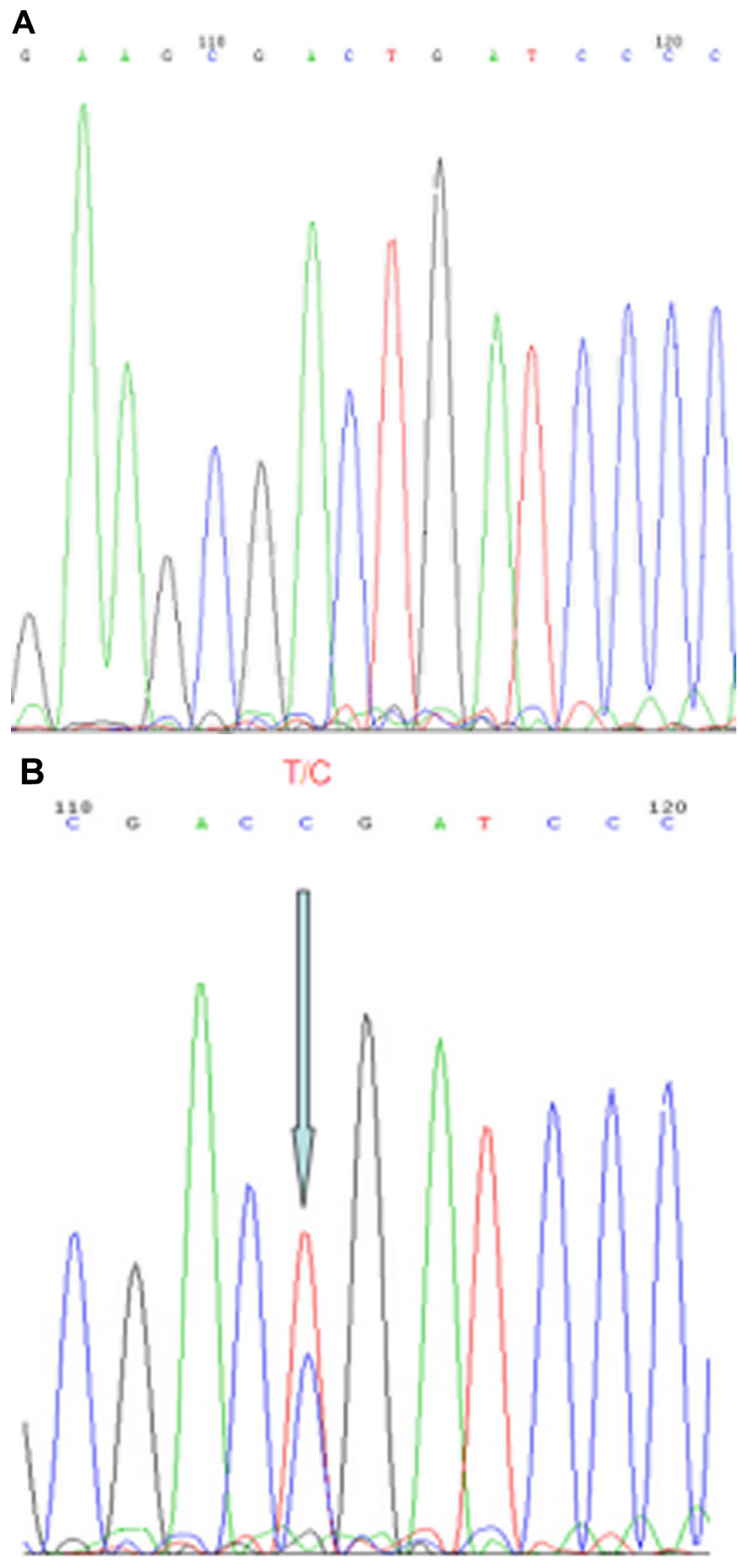

Figure 2: Representative results from Sanger sequencing for detection of the $M Y D 88$-L265P mutation. Arrows indicate the wild-type genotype in PBL patients (A) and the heterozygous mutation in a testis DLBCL patient (B). MYD88: Myeloid differentiation factor 88 . 
Table 6: Antibodies for immunohistochemistry

\begin{tabular}{lcccc}
\hline & Source & Dilution & Retrieval & Detection \\
\hline CD10 & Dako, Denmark & Prediluted & & \\
CD20 & Dako, Denmark & Prediluted & & \\
MUM1 & Fuzhoumaixin, China & Prediluted & & \\
BCL-2 & Dako, Denmark & Prediluted & & \\
BCL-6 & Dako, Denmark & Prediluted & & \\
C-MYC & Fuzhoumaixin, China & Prediluted & Citrate pH 6.0/ & EnVision, Dako, \\
P53 & Fuzhoumaixin, China & Prediluted & pressure method & Denmark \\
PSTAT3 & Abcam, USA & $1: 150$ & & \\
P50 & Abcam, USA & $1: 300$ & & \\
P65 & Abcam, USA & $1: 500$ & & \\
PIM1 & Abcam, USA & $1: 300$ & & \\
CXCR4 & Abcam, USA & $1: 600$ & & \\
JAK2 & Abcam, USA & $1: 500$ & & \\
\hline
\end{tabular}

Remark: CD10: cluster of differentiation 10; CD20: cluster of differentiation 20; MUM1: mutated melanoma-associated antigen 1; BCL-2: B-cell lymphoma 2; BCL-6: B-cell lymphoma 6; C-MYC: cellular myelocytomatosis oncogene; P53: phosphoprotein 53; PSTAT3: Phosphorylated signal transducer and activator of transcription 3; PIM1: proto-oncogene serine/ threonine-protein kinases; CXCR4: chemokine receptor 4; JAK2: Janus kinase 2.

$60 \%$ after CHOP and $80-90 \%$ after R-CHOP [4, 23-24].

Other studies have reported no benefit from the addition of rituximab in patients with PBL [25]. In our study, patients who received rituximab had a better prognosis than those who did not. However, the effectiveness of rituximab in PBL therapy should be confirmed in further investigations, due to the long time-span and small sample size of our study.

Due to the good prognosis of PBL, hematopoietic stem cell transplantation is rarely applied in such patients. Herein, one MCL patient and one stage-IVB DLBCL patient who received up-front high-dose chemotherapy with auto-PBSCT achieved CR and had not relapsed by the last follow-up. Although only two patients received this treatment, in our opinion, it may be the treatment of choice for patients with poor prognostic factors.

A few series have studied the prognostic significance of the phenotypic and genetic characteristics of PBL [26, 27]. In these previous reports, approximately half of the PBL-DLBCL patients demonstrated a GCB phenotype by immunohistochemistry, with high BCL-2 and/or BCL6 expression and relatively low MUM-1 expression. In our series, high percentages of BCL-2 and BCL-6 expression were also observed. Further analysis revealed that overexpression of BCL-2 was associated with a poor prognosis, consistent with previous reports. However, nearly half of the patients were positive for MUM1, which is higher than the incidence previously reported in the United States and Europe.

$\mathrm{NF}-\kappa \mathrm{B}$ is a transcription factor involved in several cellular survival pathways. It has been suggested that NF- $\kappa \mathrm{B}$ activity contributes to the pathogenesis of different types of B-cell lymphoma, especially nodal
non-GCB/activated-B-cell-type DLBCLs, although it is also encountered in a minority of GCB-type DLBCLs [28]. Recently, Koens et al. used immunohistochemical staining to study the NF-KB pathway in PBL [29]. They identified nuclear staining for P50 in 18\% of PBL patients, but found no patients who were positive for C-REL or P65. The authors concluded that the NF- $\mathrm{kB}$ pathway is not an attractive therapeutic target in PBL. Similarly, in our study, P50 and P65 were strongly expressed in $22.2 \%$ and $33.3 \%$ of PBL patients, respectively, with no association with cellular origin. In further analysis, there was no correlation between OS and the expression of P50 or P65.

Previous reports have suggested that the overexpression of JAK2 is important in Hodgkin lymphoma and myeloproliferative neoplasms [30]. In our series, high expression of JAK2 was also observed in tumor cells, which may indicate that JAK2 is a prognostic biomarker in PBL. Furthermore, we discovered a high expression rate of C-MYC, PSTAT3, and PIM1 in PBL tumor cells. Although they had no significant correlation with OS, these proteins may also be prognostic markers, but this requires further investigation.

MYD88 is an adaptor molecule for Toll-like receptor and interleukin-1 receptor signaling. Recently, next-generation DNA sequencing has demonstrated that functionally active mutations of MYD 88 are present in a substantial percentage of DLBCLs, and are more frequently detected in extranodal DLBCLs. The most common mutation is MYD88-L265P, which significantly contributes to the constitutive activation of the NF$\kappa \mathrm{B}$ pathway in lymphomagenesis [12-18]. Although the MYD88 mutation has been investigated in several extranodal DLBCLs (such as primary central nervous 
system DLBCL, testicular DLBCL, cutaneous DLBCL (leg type), and breast DLBCL), studies on the MYD88 mutation in PBL have been limited, and the clinical significance of the MYD 88 mutation has remained unclear. We are the first to report the MYD88-L265P mutation status of PBL patients. In our cohort, all 18 evaluable cases harbored wild-type MYD88, which implies that PBL has a relatively indolent clinical course and an excellent prognosis compared with other extranodal lymphomas. This further demonstrated that the NF- $\kappa$ B pathway may not be an attractive pathway for targeted therapy in PBL.

\section{MATERIALS AND METHODS}

\section{Patients and tissue materials}

Clinical histories and paraffin-embedded material from 19 patients presenting with PBL were retrieved from the archives and pathology department of the Nanjing Drum Tower Hospital. All cases were diagnosed and treated at the Nanjing Drum Tower Hospital between 2009 and 2015. Only cases fulfilling the criteria for the diagnosis of PBL (bone lesion \pm local soft tissue component as the primary site of presentation, without evidence of disease elsewhere within a six-month period) were included in the study. Clinicopathological features including pathological patterns, sex, age and anatomic location were evaluated. The study was approved by the local ethics committee.

\section{Immunohistochemistry}

The antibodies and conditions of the immunohistochemical staining are listed in Table 6 . Immunohistochemical staining was performed on formalin-fixed, paraffin-embedded tissue (FFPE), and the EnVision System (DAKO, Glostrup, Denmark) was used for visualization. The relative proportion of positivelystained tumor cells was considered, but not the staining intensity. All markers were considered $1+$ if $5-25 \%$ of the lymphoma cells were positive for expression, $2+$ if 25 $75 \%$ of the lymphoma cells were positive for expression, and $3+$ if more than $75 \%$ of the lymphoma cells were positive for expression.

\section{DNA extraction}

Five to ten $10-\mu \mathrm{m}$ thick serial sections were cut from FFPE tissue blocks from 18/19 patients, and the most lymphoma cell-rich area was dissected with a scalpel. Total genomic DNA was subsequently extracted with the OMEGA FFPE DNA kit (Omega Bio-tek, Norcross, GA, USA) according to the manufacturer's protocol.

\section{Mutational testing of $M Y D 88$-L265P}

For MYD88-L265P mutation analysis, the following primers were used: forward primer,
5'-TTTGTGTGAGTGAATGTGTGC-3'; reverse primer, 5'-GCTGGCTCTGCTGGTCCTT-3'. The polymerase chain reaction conditions were $94^{\circ} \mathrm{C}$ for $10 \mathrm{~min}$, followed by 10 cycles of $94^{\circ} \mathrm{C}$ for $50 \mathrm{~s}, 62^{\circ} \mathrm{C}$ for $50 \mathrm{~s}$, and $72^{\circ} \mathrm{C}$ for $50 \mathrm{~s}$, and 30 cycles of $94^{\circ} \mathrm{C}$ for $50 \mathrm{~s}, 56^{\circ} \mathrm{C}$ for 50 $\mathrm{s}$, and $72^{\circ} \mathrm{C}$ for $50 \mathrm{~s}$, with a final extension at $72^{\circ} \mathrm{C}$ for 10 min. DNA extracted from a testis lymphoma was used as a positive control. Sanger sequencing of the amplicon was performed with each forward primer, the BigDye Terminator v1.1 Cycle Sequencing Kit and the ABI3500DX Genetic Analyzer (Life Technologies, Indianapolis, IN, USA).

\section{Statistical analysis}

Statistical analysis was performed with SPSS 19.0 software (Chicago, IL, USA). $\chi^{2}$ and Fisher's exact tests were used to compare categorical variables between the two groups. The log-rank test was used to determine the prognostic impact of each immunophenotypic marker. Pearson's chi-squared test and the Kaplan-Meier method were applied to determine the clinicopathological prognostic factors influencing OS. Results were considered to be statistically significant when $P$ was $<0.05$.

\section{ACKNOWLEDGMENTS AND FUNDING}

We would like to thank our hospital's pathologist, Jieyu Chen, who performed the immunohistochemical staining. This study was supported by the Medical Science and Technology Development Foundation of Nanjing Department of Health (YKK14056).

\section{CONFLICTS OF INTEREST}

The authors have no competing interests.

\section{REFERENCES}

1. Ramadan KM, Shenkier T, Sehn LH, Gascoyne RD, Connors JM. A clinicopathological retrospective study of 131 patients with primary bone lymphoma: a populationbased study of successively treated cohorts from the British Columbia Cancer Agency. Ann Oncol. 2007; 18:129-135.

2. López-Guillermo A, Colomo L, Jiménez M, Bosch F, Villamor N, Arenillas L, Muntañola A, Montoto S, Giné E, Colomer D, Beà S, Campo E, Montserrat E. Diffuse large B-cell lymphoma: clinical and biological characterization and outcome according to the nodal or extranodal primary origin. J Clin Oncol. 2005; 23:2797-2804.

3. Messina C, Ferreri AJM, Govi S, Bruno-Ventre M, Gracia Medina EA, Porter D, Radford J, Heo DS, Park HY, Pro B, Jayamohan J, Visco C, Scarfò L, et al. International Extranodal Lymphoma Study Group (I.E.L.S.G.). Clinical features, management and prognosis of multifocal primary bone lymphoma: a retrospective study of the International 
Extranodal Lymphoma Study group (the IELSG 14 study). Br J Haematol. 2014; 164:834-840.

4. Wu H, Zhang L, Shao H, Sokol L, Sotomayor E, Letson D, Bui MM. Prognostic significance of soft tissue extension, international prognostic index, and multifocality in primary bone lymphoma: a single institutional experience. Br J Haematol. 2014; 166:60-68.

5. Messina C, Christie D, Zucca E, Gospodarowicz M, Ferreri AJ. Primary and secondary bone lymphomas. Cancer Treat Rev. 2015; 41:235-246.

6. Ding BB, Yu JJ, Yu RYL, Mendez LM, Shaknovich R, Zhang Y, Cattoretti G, Ye BH. Constitutively activated STAT3 promotes cell proliferation and survival in the activated B-cell subtype of diffuse large B-cell lymphomas. Blood. 2008; 111:1515-1523.

7. Pu HH, Duan J, Wang Y, Fan DX, Li DJ, Jin LP. Thymic stromal lymphopoietin promotes the proliferation of human trophoblasts via phosphorylated STAT3-mediated c-Myc upregulation. Placenta. 2012; 33:387-391.

8. Johnson NA, Savage KJ, Ludkovski O, Ben-Neriah S, Woods R, Steidl C, Dyer MJ, Siebert R, Kuruvilla J, Klasa R, Connors JM, Gascoyne RD, Horsman DE. Lymphomas with concurrent BCL2 and MYC translocations: the critical factors associated with survival. Blood. 2009; 114:2273-2279.

9. Brault L, Menter T, Obermann EC, Knapp S, Thommen S, Schwaller J, Tzankov A. PIM kinases are progression markers and emerging therapeutic targets in diffuse large B-cell lymphoma. Br J Cancer. 2012; 107:491-500.

10. Compagno M, Lim WK, Grunn A, Nandula SV, Brahmachary M, Shen Q, Bertoni F, Ponzoni M, Scandurra M, Califano A, Bhagat G, Chadburn A, DallaFavera R, et al. Mutations of multiple genes cause deregulation of NF- $\mathrm{BB}$ in diffuse large B-cell lymphoma. Nature. 2009; 459:717-721.

11. Lim KH, Yang Y, Staudt LM. Pathogenetic importance and therapeutic implications of NF- $\mathrm{BB}$ in lymphoid malignancies. Immunol Rev. 2012; 246:359-378.

12. Varettoni M, Arcaini L, Zibellini S, Boveri E, Rattotti S, Riboni R, Corso A, Orlandi E, Bonfichi M, Gotti M, Pascutto C, Mangiacavalli S, Croci G, et al. Prevalence and clinical significance of the MYD88 (L265P) somatic mutation in Waldenström's macroglobulinemia and related lymphoid neoplasms. Blood. 2013; 121:2522-2528.

13. Oishi N, Kondo T, Nakazawa T, Mochizuki K, Tanioka F, Oyama T, Yamamoto T, Iizuka J, Tanabe K, Shibata N, Kirito K, Katoh R. High prevalence of the MYD88 mutation in testicular lymphoma: immunohistochemical and genetic analyses. Pathol Int. 2015; 65:528-535.

14. Caner V, Sen Turk N, Baris IC, Cetin GO, Tepeli E, Hacioglu S, Sari I, Zencir S, Dogu MH, Bagci G, Keskin A. MYD88 expression and L265P mutation in mature B-cell non-Hodgkin lymphomas. Genet Test Mol Biomarkers. 2015; 19:372-378.
15. Gonzalez-Aguilar A, Idbaih A, Boisselier B, Habbita N, Rossetto M, Laurenge A, Bruno A, Jouvet A, Polivka M, Adam C, Figarella-Branger D, Miquel C, Vital A, et al. Recurrent mutations of MYD88 and TBL1XR1 in primary central nervous system lymphomas. Clin Cancer Res. 2012; 18:5203-5211.

16. Brenner I, Roth S, Flossbach L, Wobser M, Rosenwald A, Geissinger E. Lack of myeloid differentiation primary response protein MyD88 L265P mutation in primary cutaneous marginal zone lymphoma. Br J Dermatol. 2015; 173:1527-1528.

17. Bonzheim I, Giese S, Deuter C, Süsskind D, Zierhut M, Waizel M, Szurman P, Federmann B, Schmidt J, QuintanillaMartinez L, Coupland SE, Bartz-Schmidt KU, Fend F. High frequency of MYD88 mutations in vitreoretinal B-cell lymphoma: a valuable tool to improve diagnostic yield of vitreous aspirates. Blood. 2015; 126:76-79.

18. Taniguchi K, Takata K, Chuang SS, Miyata-Takata T, Sato Y, Satou A, Hashimoto Y, Tamura M, Nagakita K, Ohnishi N, Noujima-Harada M, Tabata T, Kikuti YY, et al. Frequent MYD88 L265P and CD79B Mutations in Primary Breast Diffuse Large B-Cell Lymphoma. Am J Surg Pathol. 2016; 40:324-334.

19. Parker F Jr, Jackson H Jr. Primary reticulum cell sarcoma of bone. Mod Radi Oncol. 1984; 2:383-395.

20. Cai L, Stauder MC, Zhang YJ, Poortmans P, Li YX, Constantinou N, Thariat J, Kadish SP, Nguyen TD, Kirova YM, Ghadjar P, Weber DC, Bertran VT, et al. Earlystage primary bone lymphoma: a retrospective, multicenter Rare Cancer Network(RCN) study. Int J Radiat Oncol Biol Phys. 2012; 83:284-91.

21. Demircay E, Hornicek FJ Jr, Mankin HJ, Degroot H. Malignant lymphoma of bone: a review of 119 patients. Clin Orthop Relat Res. 2013; 471:2684-2690.

22. Bruno Ventre M, Ferreri AJ, Gospodarowicz M, Vogelius I, Yahalom J. Clinical features, management, and prognosis of an international series of 161 patients with limited-stage diffuse large B-cell lymphoma of the bone (the IELSG-14 study). Oncologist. 2014; 19:291-298

23. Yuste AL, Segura A, López-Tendero P, Gironés R, Montalar J, Gómez-Codina J. Primary lymphoma of bone: a clinico-pathological review and analysis of prognostic factors. Leuk Lymphoma. 2004; 45:853-855.

24. Beal K, Allen L, Yahalom J. Primary bone lymphoma: Treatment results and prognostic factors with long-term follow-up of 82 patients. Cancer. 2006; 106:2652-2656.

25. Kim SY, Shin DY, Lee SS, Suh C, Kwak JY, Kim HG, Lee JH, Lee SI, Lee YR, Kang SH, Mun SK, Lee MJ, Lee HR, et al. Clinical characteristics and outcomes of primary bone lymphoma in Korea. Korean J Hematol. 2012; 47:213-218.

26. de Leval L, Braaten KM, Ancukiewicz M, Kiggundu E, Delaney T, Mankin HJ, Harris NL. Diffuse large B-cell lymphoma of bone: an analysis of differentiation-associated 
antigens with clinical correlation. Am J Surg Pathol. 2003; 27:1269-1277.

27. Adams H, Tzankov A, d'Hondt S, Jundt G, Dirnhofer S, Went P. Primary diffuse large B-cell lymphomas of the bone: prognostic relevance of protein expression and clinical factors. Hum Pathol. 2008; 39:1323-1330.

28. Compagno M, Lim WK, Grunn A, Mutations of multiple genes cause deregulation of $\mathrm{NF}-\kappa \mathrm{B}$ in diffuse large B-cell lymphoma. Mutations of multiple genes cause deregulation of NF- $\mathrm{kB}$ in diffuse large B-cell lymphoma. Nature. 2009; 459:717-721.
29. Koens L, Heyning FH, Szepesi Á, Matolcsy A, Hogendoorn PC, Jansen PM. Nuclear factor- $\kappa$ B activation in primary lymphoma of bone. Virchows Arch. 2013; 462:349-354.

30. Vainchenker W, Constantinescu SN. JAK/STAT signaling in hematological malignancies. Oncogene. 2013; 32:2601-2613. 